\title{
Analysis and vulnerability of the international wheat trade network
}

\author{
E. Gutiérrez-Moya ${ }^{1} \cdot$ B. Adenso-Díaz ${ }^{2} \cdot$ S. Lozano ${ }^{1}$
}

Received: 17 May 2019 / Accepted: 30 October 2020 / Published online: 16 November 2020

(C) International Society for Plant Pathology and Springer Nature B.V. 2020

\begin{abstract}
Wheat is one of the three basic cereals providing the necessary calorific intake for most of the world's population. For this reason, its trade is critical to many countries in order to fulfil their internal demand and strategic stocks. In this paper, we use complex network analysis tools to study the international wheat trade network and its evolving characteristics for the period 2009-2013. To understand the vulnerability of each country's dependence on the imports of this crop we have performed different analyses, simulating shocks of varying intensities for the main wheat producers, and observed the population affected by the production drop. As a result, we conclude that globally the network is slightly more resilient than four years previously, although at the same time some developing countries have slipped into a vulnerable situation. We have also analysed the effects of a global shock affecting all major producers, assessing its impact on every country. Some comments on the COVID-19 outbreak and the political decisions taken by governments following the pandemic declaration are included, observing that given their capital-intensive characteristics, no negative effects should currently be expected in the wheat market.
\end{abstract}

Keywords Global wheat trade $\cdot$ Complex network analysis · Supply shocks · Food crises · Vulnerability

\section{Introduction}

Historically, wheat has been the basic crop in western countries. In fact, today it is the third largest produced cereal (after rice and corn) and the second largest (after rice) for human consumption worldwide (FAO, 2018). Regarding the calorific content of the human diet, wheat represents the highest percentage of calories $(20.4 \%$ according to data of 2009 , D'Odorico et al., 2014). For this reason, everything related to its production and trade is of paramount importance to millions of people who have wheat as their basic daily sustenance.

\footnotetext{
E. Gutiérrez-Moya egm@us.es

B. Adenso-Díaz adenso@uniovi.es

S. Lozano

slozano@us.es

1 Department of Industrial Management, Universidad de Sevilla, Sevilla, Spain

2 Engineering School, Campus Gijón, Universidad de Oviedo, Oviedo, Spain
}

As the world population grows and the demand for bio fuels increase, the price of wheat has risen dramatically for some time. In addition, periodic cases of adverse weather conditions have meant that not only is it more expensive for countries to buy the required wheat, but in some cases there have been shortages, generating political instability in various parts of the world. The social movements in Northern Africa and East Asia (the so-called "Arab Spring") confirm this statement, changing the geopolitical reality in those regions as a result of a heat wave affecting production in Russia (d'Amour et al., 2016).

Unfortunately, this variability in weather conditions, increases in temperature, extreme rainfall and the presence of droughts, tend to occur more and more frequently. Fraser et al. (2013) used some hydrological models to identify the regions more exposed to climatic stress considering different cereals. Regarding wheat, the regions more exposed to droughts and with a reduced adaptability capacity are southeast USA, southeast South America, northeast Mediterranean region and Central Asia.

As agriculture is very dependent on climatic conditions, these changes cause supply shocks, affecting availability of wheat in producer and importer countries. Uncertainty of crop yields and price volatility will be a common situation to 
confront in the near future, and escalating demand is not likely to be fully met (D'Odorico et al., 2014). According to d'Amour et al.'s (2016) estimations, just a 10\% reduction in the exports of the three main crops (rice, wheat and corn) would affect by $5 \%$ the calorific intake of 55 million people living in Africa.

Currently, only through international trade can the food requirements of the world population be covered. In the last 50 years food exports have grown at an exponential rate, higher than the production growth (Ercsey-Ravasz et al., 2012). During the period 2009-2013, USA ranked first among wheat exporters, with an export volume of around 31.14 million tonnes, followed by Australia (22.51 million tonnes) and France (20.59 million tonnes). The leading wheat importing country was Egypt, with an import volume of 11.73 million tonnes, followed by Algeria (7.75 million tonnes) and Italy (7.44 million tonnes). Regarding wheat production, China ranked first, with a production of 118.13 million tonnes, followed by India (87.35 million tonnes) and USA (58.93 million tonnes) (see Table S1 in the supplementary material for further details).

According to D'Odorico et al. (2014) nearly one quarter of the total food consumed is obtained by importing from other countries. In many cases, it is the lack of the necessary water to produce those foods that makes this trade essential. But as production uncertainty and price volatility are more recurrent facts, food security for many countries becomes an issue. Theoretically, a global market makes the system more resilient as local shocks can be compensated by sourcing from areas further afield; however, if the shocks are of high intensity or occur over a wide region, this global sourcing cause severe vulnerability to the system (Jones and Phillips, 2016)

Different researchers have studied the international wheat trade and countries' vulnerabilities to supply shocks. The Bonilla Index (BI, ratio of national food import to the value of national total exports) has been proposed as a measure of the food security of a developing country (Larochez-Dupraz and Huchet-Bourdon, 2016). Countries with low BI values would have the financial resources to react to food price hikes. However, when production or other types (e.g. geopolitical or global health) of crises occur, food sourcing becomes complex and dependent on additional aspects (countries affected, international relationships, restrictive trade policies by major exporters to stabilise domestic supply, etc).

The main goal of this research is to ascertain how vulnerable the wheat world trade network is to supply shocks of varying extensions and intensities. To this end, we need to use data on wheat production, national stocks and population of various countries as well as the trade flows between them. The optimum method to model these trade flows is as a weighted directed network. Hence it is interesting also to use metrics derived from complex networks analysis (CNA) to better understand the structure of the global wheat trade system and see if this can partly explain the vulnerability results. Thus, for example, as stated by Kummu et al. (2020), countries depending on imports from a few trading partners are in a vulnerable position.

We understand vulnerability as the exposure of any agent, given its current trading partners, or of the whole system, given its network topology, to the risk that any unplanned event would produce scarcity of the given staple in the short-term, thus not satisfying the needs of the population. We want to test whether the number of people affected by severe wheat shock production has increased in recent years, or if on the contrary, the global situation is improving. By simulating a number of different situations and crisis intensities, we estimate the population affected by those events at country level, and how this vulnerability has been changing in the studied period. By repeating the simulation five years later and comparing the results, we will check how the vulnerability has evolved in this period, providing a general idea of the network resilience. Regarding the COVID-19 outbreak, we also estimate the effects of a possible global supply shock on the international wheat trade, considering varying intensity scenarios.

The remainder of the paper is as follows. In section 2 we present a review of some previous papers dealing with wheat trade modelling using the methodology proposed here, CNA. In section 3 the results of our analysis of wheat trade (taking 5year data) are presented. In section 4 we explain the vulnerability simulations carried out and show our results for the various scenarios. The discussion of those results and their implications are presented in Section 5.

\section{CNA Modelling for studying wheat trade}

As mentioned above, a number of papers have also used CNA techniques to study agri-food trade, mainly at a global level. Usually in these types of networks, each node represents a country and the edges indicate the different trade flows between them. The aim is to better understand the characteristics of the global trade and the position of each country. For instance, nodes with many inbound arcs have an advantageous position as they have more sourcing alternatives. Similarly, nodes with many outgoing links have a central role in the network as they export to many countries.

This literature review focusses on two threads of paper. On the one hand we consider studies that basically use CNA techniques to analyse the structure of the global wheat trade network, often considered together with other crops (such as maize or rice). The second group of papers deals with the analysis of the vulnerability of countries to supply shocks.

Table 1 provides a summary of wheat-centred CNA studies. As mentioned above, some of the studies (e.g. Wang 
Table 1 Summary of complex network and vulnerability analyses of wheat trade

\begin{tabular}{|c|c|c|c|}
\hline Crop & Country (Year) & Remarks & Reference \\
\hline Wheat & 76 countries (2009) & $\begin{array}{l}\text { Binary and weighted directed network; Network measures (degree } \\
\text { centrality, Bonacich power, Betweenness centrality and flow } \\
\text { centrality) }\end{array}$ & Wang (2010) \\
\hline Wheat and rice & $\begin{array}{l}191-233 \text { countries for wheat } \\
173-218 \text { for rice (1992-2009) }\end{array}$ & $\begin{array}{l}\text { Wheat Trade Network; Rice Trade Network; Weighted directed } \\
\text { networks; Network measures (in-out degree, in-out strength); } \\
\text { Self-sufficiency ratio; Food supply shocks (two end-member } \\
\text { scenarios: static and dynamic accounting) }\end{array}$ & $\begin{array}{l}\text { Puma et al. } \\
\text { (2015) }\end{array}$ \\
\hline 309 crops and animal products & 253 countries (1986-2008) & $\begin{array}{l}\text { GVWTN Weighted directed network; Density, degree, strength, } \\
\text { assortativity, clustering, centralization }\end{array}$ & $\begin{array}{l}\text { Sartori and } \\
\text { Schiavo } \\
(2015)\end{array}$ \\
\hline Wheat, Maize and Rice & $(2007-2011)$ & $\begin{array}{l}\text { Vulnerability analysis, First-round effects, international grain } \\
\text { market shocks translated to domestic grain markets, number of } \\
\text { poor people affected. }\end{array}$ & $\begin{array}{l}\text { d'Amour et al. } \\
\text { (2016) }\end{array}$ \\
\hline $\begin{array}{l}\text { Seafood products for human } \\
\text { consumption }\end{array}$ & $\begin{array}{l}205 \text { reporting territories grouped } \\
\text { into } 18 \text { regions }(2011)\end{array}$ & $\begin{array}{l}\text { Global trade network of Fish and other aquatic foods; } \\
\text { Forward-propagation model, Vulnerability analysis }\end{array}$ & $\begin{array}{l}\text { Gephart et al. } \\
\text { (2016) }\end{array}$ \\
\hline $\begin{array}{l}\text { Barley, corn, rye, millet, mixed } \\
\text { grain, oats, rice, sorghum, } \\
\text { wheat }\end{array}$ & $\begin{array}{l}\text { 1994-1998, 2001-2005, } \\
\text { 2007-2011 (162, } 164 \text { and } 165 \\
\text { countries, respect.) }\end{array}$ & $\begin{array}{l}\text { Weighted directed networks; Dynamic simulation of the } \\
\text { short-term response to a food supply shock originating in a } \\
\text { single country, Propagation analysis }\end{array}$ & $\begin{array}{l}\text { Marchand et al. } \\
\text { (2016) }\end{array}$ \\
\hline Agricultural commodities & $(1986-2011)$ & $\begin{array}{l}\text { GVWTN Weighted directed network; Propagation model, } \\
\text { Impact and vulnerability measure }\end{array}$ & $\begin{array}{l}\text { Tamea et al. } \\
\text { (2016) }\end{array}$ \\
\hline Wheat & $(1986-2011)$ & $\begin{array}{l}\text { Network formation model of global (unweighted) wheat trade } \\
\text { network; Short- and medium-term changes in network mea- } \\
\text { sures (average path length, assortativity, clustering coefficient) } \\
\text { in response to random and selective shocks of different severity } \\
\text { and length }\end{array}$ & $\begin{array}{r}\text { Fair et al. } \\
\text { (2017) }\end{array}$ \\
\hline Wheat & 194 countries-areas (2004-2014) & $\begin{array}{l}\text { Wheat-trading weighted competition network; Network measures } \\
\text { (degree, density, clustering coefficient, average path length, } \\
\text { core-periphery model, competitive direct/indirect intensity) }\end{array}$ & $\begin{array}{l}\text { Dong et al. } \\
\quad(2018)\end{array}$ \\
\hline $\begin{array}{l}16 \text { most internationally traded } \\
\text { staple food commodities }\end{array}$ & 178 countries (1986-2013) & $\begin{array}{l}\text { International food trade multi-network (weighted directed); } \\
\text { Network measures (density, bilateral density, weighted } \\
\text { asymmetry, size of largest connected component, centralisation, } \\
\text { binary/weighted assortativity, binary/weighted average } \\
\text { clustering, link weights); Community structure } \\
\text { Econometric models }\end{array}$ & $\begin{array}{l}\text { Torreggiani } \\
\text { et al. (2018) }\end{array}$ \\
\hline Maize, Rice, Soy and Wheat & 176 countries (1992-2013) & $\begin{array}{l}\text { Weighted directed networks; High-order-trade dependency net- } \\
\text { works } \\
\text { Alternative shocks responses (equal shock/proportional shock) are } \\
\text { integrated in a cascade model }\end{array}$ & $\begin{array}{l}\text { Burkholz and } \\
\text { Schweitzer } \\
\text { (2019) }\end{array}$ \\
\hline 10 imported cereals & 221 countries (1986-2013) & $\begin{array}{l}\text { Weighted bi-directed networks; Network resilience analysis upon } \\
\text { three subnetworks (backbone, intermediate, transient) } \\
\text { Network measures (degree distribution, assortativity, coefficient, } \\
\text { neighbour connectivity, clustering coefficients, shortest path) }\end{array}$ & $\begin{array}{l}\text { Dupas et al. } \\
\quad(2019)\end{array}$ \\
\hline $\begin{array}{l}\text { Bananas, Rice, Beans-dry, } \\
\text { Maize, Potatoes, Wheat }\end{array}$ & $\begin{array}{l}\text { Nile basin countries } \\
\quad(2000-2013)\end{array}$ & $\begin{array}{l}\text { GVWTN Weighted directed network; Network measures (degree, } \\
\text { eigenvector centrality, average clustering coefficient, average } \\
\text { path length) }\end{array}$ & $\begin{array}{l}\text { Selim and } \\
\text { Abdalbaki } \\
\text { (2019) }\end{array}$ \\
\hline $\begin{array}{l}\text { Cereal grains, animal feed and } \\
\text { products of animal origin }\end{array}$ & $\begin{array}{l}50 \text { states plus district of } \\
\text { Columbia (2012) }\end{array}$ & $\begin{array}{l}\text { Domestic food transfer network (weighted directed); } \\
\text { Network measures (pointwise mutual information, degree, } \\
\text { strength, degree centrality) }\end{array}$ & $\begin{array}{l}\text { Vora et al. } \\
\text { (2019) }\end{array}$ \\
\hline
\end{tabular}

2010, Fair et al. 2017, Dong et al. 2018) consider just wheat trade, while others consider wheat together with other crops (e.g. Sartori and Schiavo, 2015, d'Amour et al., 2016, Burkholz and Schweitzer 2019). The pioneering work of Wang (2010) considers 76 countries and 183 trade wheat relationships in single year of 2009 revealing that bargaining in the wheat trade network inclines towards exporting countries.
Puma et al. (2015) assess changes in connectivity within the global wheat and rice trade networks focussing on the average values for two time periods (1992-1996; 2005-2009). Continuing with Puma et al. (2019)'s work, our study focusses on the five-year data following the latest world crisis in 2008, that, particularly in the case of wheat, chiefly affected developing countries that in most instances are net importers. 
Other studies analysed competitive relationships among wheat importers (Dong et al. 2018) and international food trade in terms of the corresponding amount of calories (Torreggiani et al. 2018). Although not included in Table 1, it is interesting to note also the study of Ercsey-Ravasz et al. (2012), which relates the international food trade network (1988-2008) (in currency units of trade fluxes) to food safety through the transfer of contaminants across borders.

From another perspective, Dupas et al. (2019) analyse cereals' trade according to their temporal stability, introducing the concept of a backbone food subnetwork during the period from 1986 to 2013, detecting invariant structures that provide flexibility to perturbations and shocks. Selim and Abdalbaki (2019) use the concept of virtual water to study trade flows of all types of agricultural products. Recently, the dependencies arising from interlinkages among food, energy, water resources and trading partners have also been addressed through a nexus approach (Vora et al. 2019).

Sartori and Schiavo (2015) aimed at characterising the corresponding weighted directed network, analysing its in- and out-degree and in- and out-strength distribution, average clustering coefficient, assortativity, community structure and node centrality measures during the period 1986-2010. A different approach is presented in Fair et al. (2017), in which a calibrated preferential attachment network formation model is used to measure the evolution of the network (in terms of its density, symmetry, average path length, clustering coefficient, assortativity, etc.) in response to shocks of varying severity and duration - shocks that can be random (errors) or selective (targeted attacks). Torreggiani et al. (2018) address the community structure detection considering the international food trade network as a collection of separate layers; the analysis is supplemented by fitting probit and logit regression models to estimate the probability of two countries belonging to the same cluster.

Regarding the studies on the vulnerability of countries to different types of shocks originating in a single country or in a group of countries, some studies (e.g. d'Amour et al. 2016) consider only first-round effects, while others simulate the propagation of these shocks through network trade links (e.g. Tamea et al. 2016, Marchand et al. 2016, Burkholz and Schweitzer 2019). Thus, although a country's reserves (as well as domestic consumption) can partly absorb some shocks, it frequently happens that the exports of the affected countries are reduced or banned, thus propagating the initial shock. Some studies (e.g. Puma et al. 2015, Gephart et al. 2016) also take into account the demand price elasticity and the fact that richer countries have greater possibilities to pay the resulting world market price increases and secure food supplies without reducing their consumption, as poor countries may be forced to do. In general, it seems that the global food system does show features consistent with a vulnerability condition and a susceptibility to self-propagating disruptions.
Generally, vulnerability studies compute self-sufficiency ratios and vulnerability/impact indexes that, in some cases, also take into account the population size affected in different countries.

In this paper, we integrate the two threads of research reviewed above as we analyse the structure of the global wheat trade network and assess its vulnerability. Moreover, we study whether the observed vulnerability can be partially explained by the topology of the network as given by different characterisation metrics. Also, among the CNA metrics considered, we have included the PageRank index, which measures a country's centrality from the importer or exporter perspective and that to the best of our knowledge has not been used before in these types of networks.

\section{Complex network analysis of global wheat trade flows}

This section presents the characterisation, using CNA indexes and metrics, of the global Wheat Trade Network (WTN). This will allow us to understand the structure and the main features of the network. Thus, we are interested in the following: measuring different topological features such as the density of the network (i.e. what percentage of all pairs of countries trade); the extent that trade links are reciprocal (i.e. bidirectional); the transitivity (often called clustering in the CNA parlance) of the trade relationships in the WTN; the distances among the nodes in the network; what the most central countries in the global wheat trade are from an importer or an exporter point of view; whether the WTN is scale-free (i.e. its degree distribution follows a Power Law so that most countries have a small number of trading partners, however, there are a few "hub countries" that have a large number of trading links); whether there is homophily (e.g. of geographical type) so that nodes of the same type trade among themselves more than nodes of different types; whether there exist significant motifs (i.e. local connection patterns that occur with a frequency unlikely to be due to randomness); the community structure (i.e. different groups of countries that trade intensively within-group much more than with countries that belong to other groups), etc. All these questions can be effectively answered using CNA tools and techniques. That is why, as the literature review presented in the previous section shows, CNA has generally been used for this characterisation task.

Data on bilateral wheat trade flows between countries for the years 2009-2013 were obtained from the Statistics Division of the Food and Agriculture Organization (FAOSTAT, http://faostat.fao.org) and used to build a weighted, directed WTN. To smooth out fluctuations in the various years these trade flows were averaged. Table 2 shows some metrics of this 2009-2013 WTN. 
For economy of space, we do not provide the formal definition or the mathematical expressions used to compute these measures because they are well-known and can be found in any CNA textbook (e.g. Wasserman and Faust 1994) as well as in many CNA surveys (e.g. Newman 2003, Costa et al. 2007). In any case, the network density refers to the number of existing trade links as a proportion of all possible trade links. This is related to a high average in- and out-degree. The in-degree of a country is the number of countries from which it imports, while its out-degree is the number of countries to which it exports. The average path length and the network diameter are measures of how far, in terms of the number of links required to go from one node to another, the nodes are from each other. The farther a node is from a given node, the less it can be affected by it, at least in a first round.

Note that our network has a relatively high density, small average path length and diameter, high out-degree centralisation, and a high degree of reciprocity and clustering. The small distances between countries within the WTN (known in CNA parlance as a Small-World network) indicates the integrated character of the global wheat trade, which makes countries dependent of one another for their food security. The degree centralisation is an index that measures whether the similarity of the WTN to a star network, with a certain node occupying a central position. The high reciprocity index indicates a high frequency of bidirectional flows, something which may seem surprising at first sight as it might be expected that a country is either an exporter or an importer, but not both. The high average clustering coefficient indicates the likelihood that the trade partners of a given country also trade among themselves (i.e. transitivity).

Figure 1 shows two visualisations of the network using NetDraw (within the UCINET 6.0 Package, Borgatti et al., 2002). To reduce clutter, the arcs have been filtered so that only those with a weight above the third quantile (Q3) have been retained. The network is the same in both cases, except that in Fig. 1 (top panel) to emphasise imports, the size of the

Table 2 Some characterisation measures of the WTN (2009-2013)

\begin{tabular}{ll}
\hline & WTN (2009-2013) \\
\hline \# nodes & 205 \\
\# ties & 2880 \\
Density & 0.069 \\
Average geodesic distance & 2.6 \\
Diameter & 6 \\
Average degree & 28.09 \\
In/Out-degree centralisation & $0.192 / 0.601$ \\
Average strength & $1,987,868$ \\
\#mutual/\#asymm/\#null dyads & $494 / 1892 / 18,524$ \\
Arc/Dyad reciprocity & $0.341 / 0.206$ \\
Transitivity & 0.233 \\
\hline
\end{tabular}

nodes is proportional to the in-degree, while in Fig. 1 (bottom panel) exports are emphasised and the node sizes are proportional to their out-degree. To help differentiate the two visualisations of the network, in one the node shapes are circles and in the other rounded squares. ISO 3166-1 alpha-2 country codes are used to name the countries. Countries with a major importer role are Iran, Yemen, Algeria, Morocco, Tunisia, Saudi Arabia, Italy, Spain, Germany and Turkey, among others. Exporting countries with a large number of trading partners include the USA, Canada, Australia, Russia, Ukraine, Brazil, Argentina, France and Germany, among others. Note that it is not uncommon for a country to be involved simultaneously in imports and exports.

Figure 2 shows the plot of in-strength versus out-strength of the nodes. The in-strength is the sum of the weights of the arcs that enter a node (i.e. the total volume of imports of the country) while the out-strength is the sum of the weights of all the arcs that leave a node (i.e. the total exports of the country). The top right quadrant corresponds to the most active trading partners, having large in- and out-strengths. Note the prominent positions, close to the top right corner, of the USA, Germany, Brazil, Russia, France. Argentina, Ukraine and, especially, Australia exports more than they import. In contrast, countries such as Turkey, Spain and Italy import more than they export. The lower right quadrant corresponds to countries with large imports and small or no exports - countries such as South Korea, Egypt, Algeria, Yemen, Morocco, Peru and the Philippines. Excluding for Angola, the lower left quadrant corresponds mainly to small countries with small or no exports. Note that the top left quadrant is empty, i.e. we conclude that large exporters are in most cases also large importers.

An important feature of many real-world networks is their scale-free nature. To test whether WTN also has that property, a Power law (PL) fit analysis of the in-, out- and total degree and the in-, out- and total strength has been performed using the method in Clauset et al. (2009) (see Table S2 in the supplementary material for further details). In all cases, except out-degree, a PL distribution with a corresponding exponent can be fitted. This is the signature of scale-free networks and indicates a right-skewed, non-homogeneous distribution of these variables. Thus, for example, it means that most countries have fewer connections and a low trade volume and a few countries (that can be labelled as hubs) have a greater number of connections and a large trade volume. Table 3 shows the 20 top countries in terms of in- and out-degree and in- and outstrength. Note that only one country (namely, Germany), shown in bold, appears in this top-20 list for all four measures. Several other countries, however, such as the USA, Canada, France, Italy, Brazil, the UK and the Netherlands, appear in three of the four rankings. Looking at the in- and out-degrees, it can also be seen that the importing countries with the largest number of trading partners (Italy and UK) import from around 50 countries, while the exporting countries that have the 

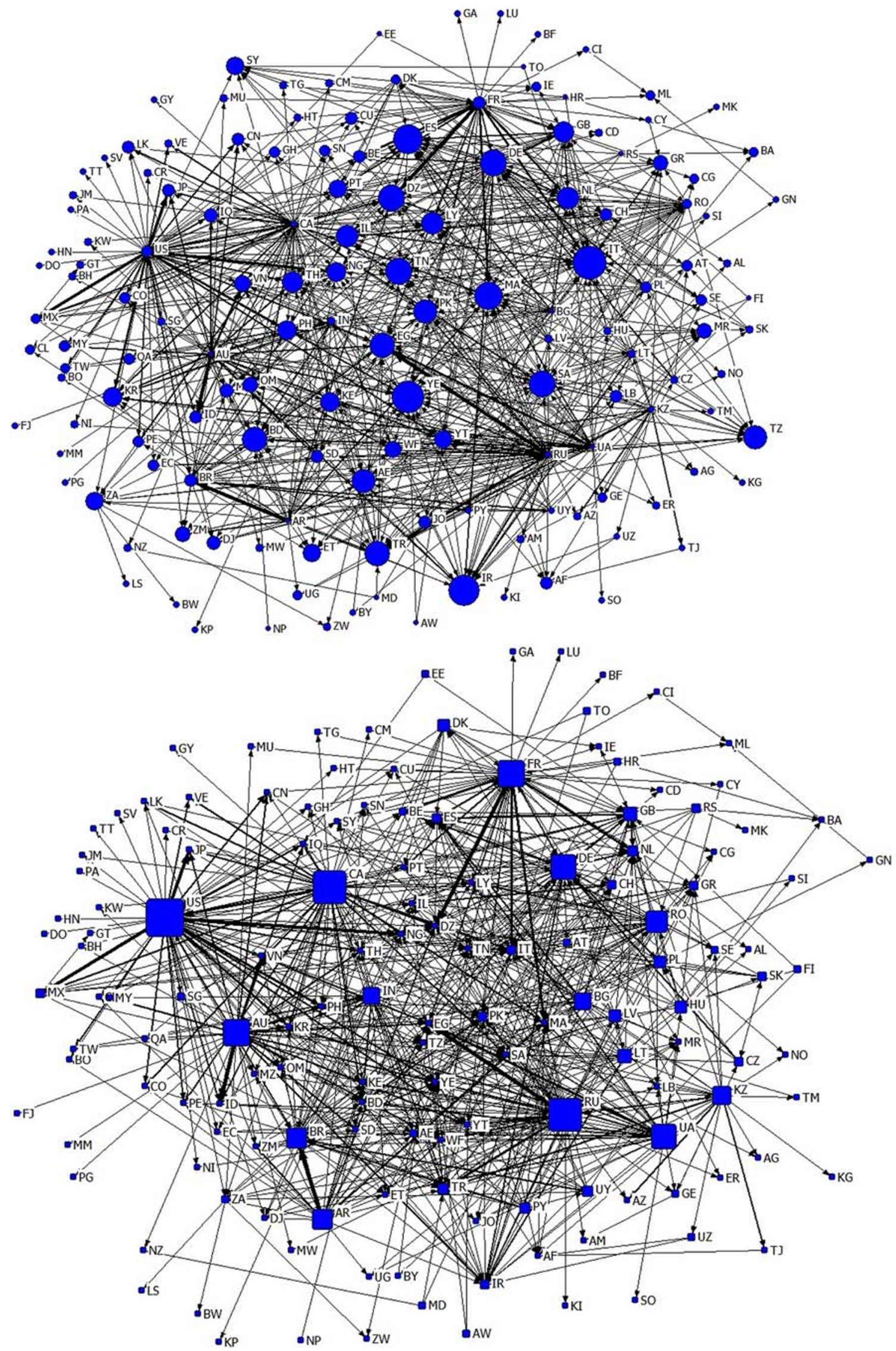

Fig. 1 Filtered WTN (2009-2013) (only arcs with weights above Q3 are shown) 
Fig. 2 In-strength versus outstrength (axes are in $\log _{10}$ scale)

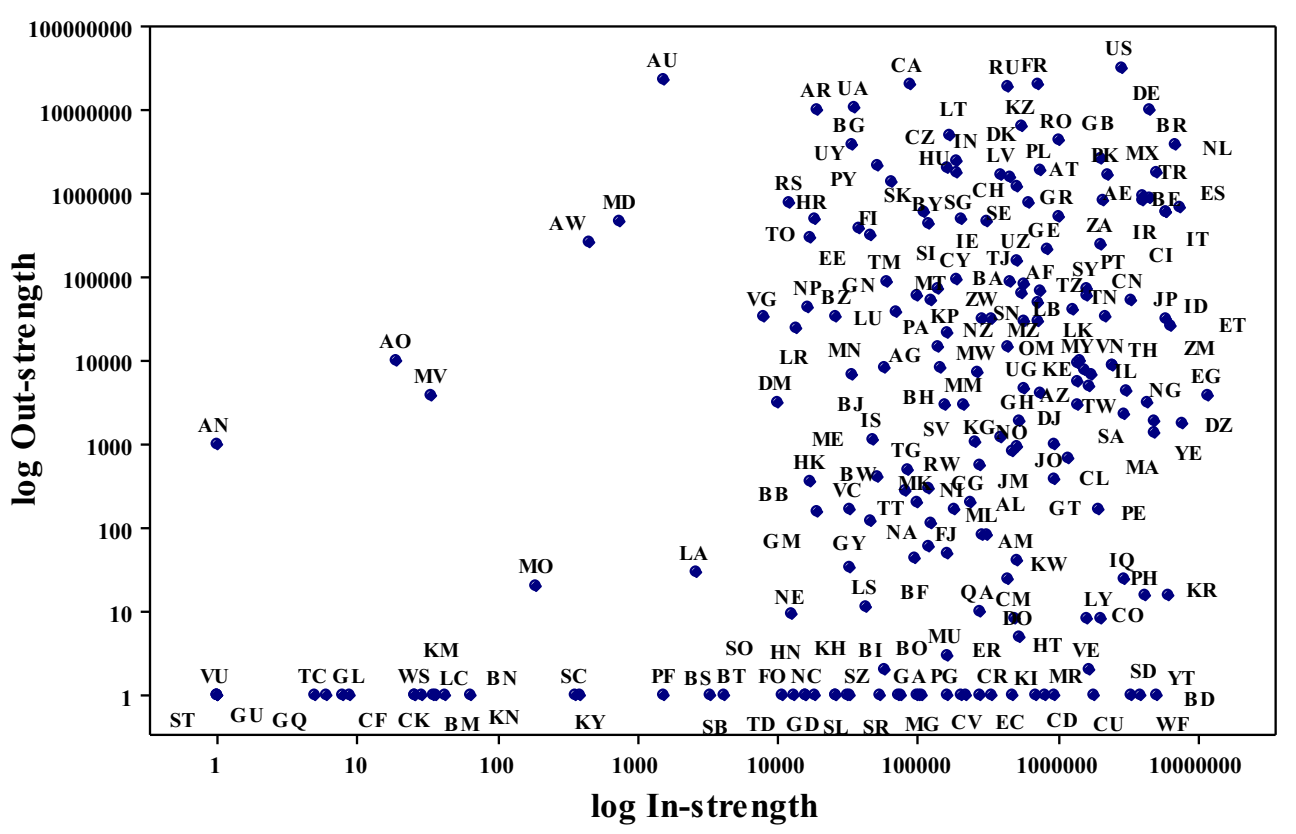

greatest number of trading partners (USA, France, Germany, Russia and Canada) export to more than 100 countries.

Following the direction of the arcs and the reverse direction, respectively, the corresponding PageRank (Brin and Page, 1998) of the countries can be computed. This is a centrality measure that indicates the probability of a node being visited by a random surfer that follows the arcs that leave (or, in the reverse direction case, that go into) a node with a probability proportional to their weights. Table 4 shows the countries with the main importer and exporter PageRank values. Note that most central countries from an import perspective are located in Africa and the Middle East, plus some countries in Europe (namely, Italy and Spain) and East Asia (namely, Pakistan, Singapore and the Philippines). The most central exporting countries are located in North and South America, Europe (including Ukraine) and Central Asia (including Russia), plus Australia and New Zealand.

Another common feature of many real-world networks is the existence of homophily, i.e. that the patterns of links between the nodes is correlated with certain node attributes. To test the hypothesis that there is geographical homophily in the WTN, i.e. that countries trade more with those countries that are closer than with those that are far away, we have considered six regions, namely North America (including Central America and the Caribbean), South America, Europe (including Ukraine), Africa, Asia (including Russia) and Oceania, so that Table 5 shows the number of arcs and the sum of the corresponding weights within and between each of these six regions. The E-I index is 0.125 in the case of the number of arcs and slightly higher, 0.295 , in the case of the sum of weights. This indicates that there are more arcs between regions than within regions and, moreover, more trade flows through the between-regions arcs than through those within- region. Thus, although the wheat trade between European countries is significant, most trade more with the rest of the world than within. An extreme case is Africa, whose trade corresponds to imports from Europe, Asia and North America, in that order. In the case of Asia, although its exports are mainly within the region, the imports come primarily from outside the region, in particular from North America and Europe, in that order. The pairs of regions for which the density of arcs is higher than the overall network density are: North-America $\leftrightarrow$ North-America, North-America $\rightarrow$ SouthAmerica, South-America $\leftrightarrow$ South-America, SouthAmerica $\rightarrow$ Africa, South-America $\rightarrow$ Asia, Europe $\leftrightarrow$ Europe, Europe $\rightarrow$ Africa, Europe $\leftrightarrow$ Asia, Asia $\leftrightarrow$ Asia, Oceania $\rightarrow$ Asia and Oceania $\leftrightarrow$ Oceania. Note also the trade balance (total exports minus total imports) for the different regions; it is positive and large for Europe and North America, positive and moderate for Oceania and South America and negative and large for Africa and Asia.

It is also interesting to find the community structure of WTN. Communities (also called modules) are groups of nodes with more connections within-groups than betweengroups. These communities involve spontaneous trading blocks and reflect multidimensional (i.e. geopolitical, historical and economic) aspects. The existence and identification of communities in a network can be found using different algorithms (see Fortunato 2010). The goal is to partition the nodes into various groups so that these groups represent "true" communities.

Many of those community detection algorithms measure the significance of a community using a measure known as modularity (Newman 2004). The modularity function measures the fraction of all the arcs that lie within communities minus the expected value in a so-called null model (i.e. a 
Table 3 Countries with highest in- and out-degree and in- and out-strength

\begin{tabular}{|c|c|c|c|c|c|c|c|c|}
\hline \multirow{2}{*}{$\begin{array}{l}\text { Rank } \\
1\end{array}$} & \multicolumn{2}{|l|}{ In-degree } & \multicolumn{2}{|l|}{ Out-degree } & \multicolumn{2}{|l|}{ In-strength } & \multicolumn{2}{|l|}{ Out-strength } \\
\hline & Italy & 53 & $U S A$ & 136 & Egypt & $11,728,660$ & $U S A$ & $31,140,952$ \\
\hline 2 & United Kingdom & 49 & France & 106 & Algeria & $7,747,467$ & Australia & $22,507,513$ \\
\hline 3 & France & 47 & Germany & 106 & Italy & $7,436,861$ & France & $20,589,849$ \\
\hline 4 & $U S A$ & 46 & Russia & 105 & Brazil & $6,747,760$ & Canada & $20,230,009$ \\
\hline 5 & Netherlands & 46 & Canada & 103 & Indonesia & $6,268,367$ & Russia & $19,333,453$ \\
\hline 6 & Germany & 45 & Ukraine & 95 & Rep of Korea & $6,030,813$ & Ukraine & $10,930,267$ \\
\hline 7 & Switzerland & 41 & Australia & 82 & Japan & $5,983,671$ & Argentina & $10,076,484$ \\
\hline 8 & Spain & 41 & Italy & 74 & Iran & $5,847,923$ & Germany & $9,728,126$ \\
\hline 9 & Turkey & 40 & Turkey & 70 & Spain & $5,818,902$ & Kazakhstan & $6,404,751$ \\
\hline 10 & Malaysia & 36 & Argentina & 66 & Netherlands & $5,105,902$ & India & $4,997,165$ \\
\hline 11 & Morocco & 36 & India & 65 & Bangladesh & $5,024,025$ & Romania & $4,284,795$ \\
\hline 12 & Israel & 36 & Romania & 63 & Yemen & $4,859,765$ & Brazil & $3,851,297$ \\
\hline 13 & Belgium & 36 & United Kingdom & 63 & Morocco & $4,846,121$ & Bulgaria & $3,746,072$ \\
\hline 14 & Canada & 34 & Brazil & 63 & Turkey & $4,523,317$ & United Kingdom & $2,583,906$ \\
\hline 15 & Uganda & 33 & Poland & 57 & Germany & $4,434,120$ & Lithuania & $2,430,304$ \\
\hline 16 & Denmark & 33 & Kazakhstan & 57 & Nigeria & $4,275,886$ & Uruguay & $2,187,734$ \\
\hline 17 & South Africa & 32 & Bulgaria & 56 & Philippines & $4,163,002$ & Hungary & $2,063,020$ \\
\hline 18 & Saudi Arabia & 32 & Netherlands & 52 & Mexico & $4,004,984$ & Poland & $1,927,757$ \\
\hline 19 & Algeria & 32 & Belgium & 50 & Belgium & $3,983,870$ & Czech Republic & $1,816,611$ \\
\hline 20 & Yemen & 31 & Lithuania & 48 & South Africa & $3,845,008$ & Netherlands & $1,726,364$ \\
\hline
\end{tabular}

Note: Countries in all four rankings are shown in bold; Countries in three of the four rankings are shown in italics

Table 4 Countries with highest PageRank centralities

\begin{tabular}{llll}
\hline Imports viewpoint & PageRank & Exports viewpoint & PageRank \\
\hline Yemen & 14.32 & Russia & 26.43 \\
Mali & 9.53 & Kazakhstan & 26.14 \\
Senegal & 9.40 & USA & 23.22 \\
Saudi Arabia & 9.15 & Canada & 22.17 \\
Italy & 5.09 & Australia & 8.01 \\
Rwanda & 4.87 & Germany & 5.15 \\
Uganda & 4.79 & France & 4.92 \\
Singapore & 4.37 & New Zealand & 4.63 \\
U. Arab Emirates & 4.36 & Hungary & 4.04 \\
Kenya & 4.14 & Paraguay & 3.36 \\
Qatar & 3.85 & Ukraine & 3.31 \\
Iran & 3.69 & Czech Republic & 3.30 \\
Israel & 3.41 & Uruguay & 3.17 \\
Jordan & 3.26 & Romania & 3.15 \\
Philippines & 2.91 & Slovakia & 2.77 \\
Spain & 2.58 & Argentina & 2.74 \\
South Africa & 2.50 & Denmark & 2.15 \\
Pakistan & 2.33 & United Kingdom & 2.14 \\
Egypt & 2.28 & Bulgaria & 2.07 \\
Syrian Arab Rep & 2.21 & Lithuania & 2.06 \\
\hline
\end{tabular}

network with the same degree distribution but with arcs generated randomly). A modularity of zero indicates that the community structure is similar to that of a random network and hence not significant. The larger the value of the modularity, the larger the deviation from randomness and the more significant the community structure. Table $\mathrm{S} 3$ in the supplementary material shows the results of the leading eigenvector (LE) community detection algorithm (Newman, 2006). The community partition found has a modularity of 0.338 and involves three large communities: one that contains the USA, Canada, Brazil, Australia, New Zealand and their corresponding trading partners (including China, India, Japan and South Korea); another group of countries formed by Russia, Ukraine, Iran, Turkey and their main trading partners (including Egypt, Israel and Pakistan); and a third cluster that contains most European countries, Argentina, Uruguay and their main trading partners (including Morocco, Algeria and South Africa).

Another aspect worth investigating is the type of local interactions within the WTN. This can be achieved byanalysing the relative frequency of each possible interconnection pattern (called motifs in CNA). The goal is to identify those motifs whose relative frequency deviates significantly from that which would be expected in a random network. The idea is that the over- or underrepresentation of those motifs in the real network must be for a reason. Moreover, motifs have been hypothesised to function as building blocks of complex 
Table 5 Cross-regional distribution of wheat trade flows (2009-2013)

\begin{tabular}{|c|c|c|c|c|c|c|c|c|}
\hline & N. Amer. & S. Amer. & Europe & Africa & Asia & Oceania & Total exports & Total exports-Total imports \\
\hline N. Amer. & $\begin{array}{l}9,102,640 \\
(55 \text { ties }) \\
\text { dens: } 0.063\end{array}$ & $\begin{array}{l}\text { 6,878,940 } \\
\text { (33 ties) } \\
\text { dens: } 0.073\end{array}$ & $\begin{array}{l}3,229,392 \\
(48 \text { ties }) \\
\text { dens: } 0.039\end{array}$ & $\begin{array}{l}10,642,190 \\
(75 \text { ties }) \\
\text { dens: } 0.045\end{array}$ & $\begin{array}{l}22,168,238 \\
\text { (81 ties) } \\
\text { dens:0.054 }\end{array}$ & $\begin{array}{l}398,643 \\
(5 \text { ties }) \\
\text { dens: } 0.012\end{array}$ & $52,420,043$ & $35,000,228$ \\
\hline S. Amer. & $\begin{array}{l}152,336 \\
(16 \text { ties }) \\
\text { dens:0.035 }\end{array}$ & $\begin{array}{l}6,874,237 \\
\text { (41 ties) } \\
\text { dens: } \mathbf{0 . 1 9 5}\end{array}$ & $\begin{array}{l}383,247 \\
(33 \text { ties }) \\
\text { dens: } 0.053\end{array}$ & $\begin{array}{l}\text { 6,994,407 } \\
(87 \text { ties }) \\
\text { dens: } 0.105\end{array}$ & $\begin{array}{l}3,204,247 \\
(56 \text { ties) } \\
\text { dens:0.075 }\end{array}$ & $\begin{array}{l}187,700 \\
(2 \text { ties }) \\
\text { dens: } 0.010\end{array}$ & $17,796,174$ & $10,570,834$ \\
\hline Europe & $\begin{array}{l}843,006 \\
(41 \text { ties) } \\
\text { dens: } 0.033\end{array}$ & $\begin{array}{l}108,433 \\
(23 \text { ties }) \\
\text { dens: } 0.014\end{array}$ & $\begin{array}{l}33,556,136 \\
\text { ( } 725 \text { ties) } \\
\text { dens: } 0.442\end{array}$ & $\begin{array}{l}22,488,764 \\
(279 \text { ties }) \\
\text { dens: } 0.124\end{array}$ & $\begin{array}{l}\text { 16,449,342 } \\
\text { (300 ties) } \\
\text { dens:0.146 }\end{array}$ & $\begin{array}{l}455,321 \\
(14 \text { ties }) \\
\text { dens: } 0.026\end{array}$ & $73,901,002$ & $34,350,843$ \\
\hline Africa & $\begin{array}{l}248 \\
(9 \text { ties }) \\
\text { dens: } 0.005\end{array}$ & $\begin{array}{l}10,005 \\
(1 \mathrm{tie}) \\
\text { dens: } 0.001\end{array}$ & $\begin{array}{l}91,610 \\
(28 \text { ties }) \\
\text { dens: } 0.012\end{array}$ & $\begin{array}{l}615,571 \\
(104 \text { ties }) \\
\text { dens: } 0.035\end{array}$ & $\begin{array}{l}211,046 \\
(41 \text { ties }) \\
\text { dens:0.014 }\end{array}$ & $\begin{array}{l}1 \\
(1 \mathrm{tie}) \\
\text { dens: } 0.001\end{array}$ & 928,481 & $-55,135,838$ \\
\hline Asia & $\begin{array}{l}442,056 \\
(39 \text { ties }) \\
\text { dens:0.026 }\end{array}$ & $\begin{array}{l}227,790 \\
(11 \text { ties }) \\
\text { dens: } 0.015\end{array}$ & $\begin{array}{l}1,904,349 \\
\text { (128 ties) } \\
\text { dens:0.062 }\end{array}$ & $\begin{array}{l}11,553,968 \\
\text { (156 ties) } \\
\text { dens: } 0.056\end{array}$ & $\begin{array}{l}\text { 20,181,328 } \\
\text { (316 ties) } \\
\text { dens:0.128 }\end{array}$ & $\begin{array}{l}1,877,232 \\
(20 \text { ties }) \\
\text { dens:0.031 }\end{array}$ & $36,186,723$ & $-42,939,956$ \\
\hline Oceania & $\begin{array}{l}589 \\
(5 \text { ties }) \\
\text { dens: } 0.013\end{array}$ & $\begin{array}{l}4875 \\
(1 \mathrm{tie}) \\
\text { dens: } 0.005\end{array}$ & $\begin{array}{l}385,425 \\
(14 \text { ties }) \\
\text { dens: } 0.026\end{array}$ & $\begin{array}{l}3,769,419 \\
(27 \text { ties }) \\
\text { dens: } 0.037\end{array}$ & $\begin{array}{l}\text { 16,912,478 } \\
\text { (42 ties) } \\
\text { dens:0.064 }\end{array}$ & $\begin{array}{l}\text { 1,448,929 } \\
(15 \text { ties }) \\
\text { dens:0.096 }\end{array}$ & $22,521,715$ & $18,153,889$ \\
\hline Total imports & $10,540,875$ & $14,104,280$ & $39,550,159$ & $56,064,319$ & $79,126,679$ & $4,367,826$ & $203,754,138$ & - \\
\hline
\end{tabular}

Note: Bold italics indicates density higher than overall network density

networks (Milo et al., 2002). Table S4 in the supplementary material shows the triad census (i.e. motifs of size three) of the WTN computed by UCINET 6.0. It was found that all transitive triads have high counts, which is consistent with the relatively high transitivity reported in Table 2 . In particular, there are 1386 cliques of size three (triad code 300 ). Recall that a clique is a set of nodes, all of which are connected between themselves (bidirectionally) and hence form a tightly connected substructure. The number of such cliques of size three in WTN is significantly higher than in a random network. A more detailed analysis of three and four-node motifs have been performed using the mfinder network motifs detection tool. Tables S5 and S6 in the supplementary material show the significant (i.e. relatively frequent compared with a null model corresponding to a similar randomised network) directed motifs found. For each motif, the observed and expected counts, the concentration, z-score and uniqueness and some examples are shown.

\section{Network vulnerability}

As mentioned above, the frequency of finding shocks in the supply network athat affect the international wheat trade has increased In addition to extreme weather conditions, political decisions are not uncommon as a response to price volatility (e.g. according to Puma et al., 2015, six of the largest wheat exporters imposed trade restrictions in 2008 to protect domestic markets), leading on occasions to a cascade effect. Jones and Phillips (2016) studied the frequency of food production shocks. They define "global shock" as the result of a major producer (or several smaller producers) experiencing a production crisis. In their study they claim that at country level a country suffers a "major shock" (loss of more than 58\%) every other year. The shocks considered in the literature are not usually as large as that. Thus, d'Amour et al. (2016) considered $10 \%$ reduction scenarios for their analysis of the effects of food shocks, while Marchand et al. (2016) used a 20\% production decrease in their simulations.

\subsection{Local shocks assessment}

To assess how robust the wheat network is, we need to focus on production shocks occurring just in some of the main traders. For the identification of the largest wheat producers we have considered the global production in the period 2009 2013 and after sorting out all the countries, we selected those representing $85 \%$ of the cumulative production. This results in 20 countries, namely: Argentina, Australia, Canada, China, Egypt, France, Germany, India, Iran, Italy, Kazakhstan, Pakistan, Poland, Romania, Russia, Turkey, Ukraine, United Kingdom, USA and Uzbekistan.

We have simulated the effects of each of these countries experiencing a production crisis, thus affecting the countries with which they trade. Let us denote by $P_{c}$ the production of country $\mathrm{c}$ in a specific year; $t_{c c^{\prime}}$ the amount of wheat exported from country c to c'; and $\Delta_{c}$ the change in the strategic reserves (positive if stocks are reduced, following FAO data standard). We could estimate the internal demand of country $\mathrm{c}$ given by

$I D_{c}=\sum_{c^{\prime}} t_{c^{\prime} c}+P_{c}+\Delta_{c}-\sum_{c^{\prime}} t_{c c^{\prime}}$ 
If we want to assess the effect on that country of a reduction of $\alpha_{c^{\prime}}$ per cent in the production of a country c', we could calculate the percentage of internal demand covered as

$I_{c, \alpha}=\frac{\sum_{c^{\prime}} \alpha_{c^{\prime}} t_{c^{\prime} c}+\alpha_{c} P_{c}+\Delta_{c}-\alpha_{c} \sum_{c^{\prime}} t_{c c^{\prime}}}{\sum_{c^{\prime}} t_{c^{\prime} c}+P_{c}+\Delta_{c}-\sum_{c^{\prime}} t_{c c^{\prime}}}$

According to d'Amour et al. (2016), vulnerability to food supply shocks can be measured by how the crisis is translated into the domestic market, and by the number of poor people affected. Note that, following our notation, the population affected by a supply shock of intensity $\alpha$ is therefore given by

$P A_{c, \alpha}=\left(1-I_{c, \alpha}\right) \cdot$ Population $_{c}$

and the global population affected would be

$G P A_{\alpha}=\sum_{c} P A_{c, \alpha}$

For our simulations, we will consider crises of different intensities ( $\alpha$ varying from $5 \%$ to $50 \%$ ) on each of the 20 major producers, occurring at one or two simultaneously. Therefore, $20+(20 \cdot 19 / 2)=210$ scenarios are considered for the simulation. It must be noted that these results must be read as the immediate effect of any shock, considering the current trading partners and stock variation. Of course, the governments may react in time to any supply shock by going to the markets and bidding to compensate for the shortfalls.

Looking at the results of the 210 simulations corresponding to the years 2009, 2011 and 2013, Fig. 3 shows the boxplot corresponding to the population affected $P A_{c, \alpha}$ by an $\alpha=$ $50 \%$ drop in production in various countries' combinations. Note that the central values changed in this period (median was $159 \mathrm{~m}$ in 2009 and $145 \mathrm{~m}$ in 2013, i.e. a 9\% reduction), and variability has become smaller in more recent years. This may be a sign that the network is becoming more resilient to this type of crisis; Fig. 4 confirms that, for different crises' intensities, during this period the population affected has decreased for all production drops.

The evolution (in the period under study, 2009-2013) of the percentage of the population $\mathrm{I}_{\mathrm{c}, 0.5}$ that is covered in each country when a 50\% drop (major shock) occurs in one of the major producers, can help to gauge how resilient each country is becoming to confront an international wheat crisis. Positive values mean that in the 5 -year period the percentage of population covered after a $50 \%$ crisis in one (or two) of the major producers has improved for that nation, while positions below 0 imply a worse situation. Figure 5 shows the position of each country considering its GDP per capita.

Displaying again the evolution of the internal demand covered in the same period under a $50 \%$ crisis, but now versus the evolution of the ratio of the internal demand that is covered by importation (i.e., $\sum_{c^{\prime}} t_{c^{\prime}}{ }^{\prime} / I D_{c}$ ), the results can be seen in Fig. 6 .
Countries in the upper-left quadrant have improved their resilience and at the same time reduced their dependence on imports. Most of those countries are in Asia. In contrast, countries in the lower-right quadrant are in a less resilient position than 5 years earlier and in addition are more dependent on imports. Many countries in Africa, America and Asia are in this position.

On some occasions, the supply problem is not directly related to a production crisis but to some political decisions. This is the case when a country decides to ban its exports, for whatever reason. Figure 7 shows the effects when one of the main producers reduces its wheat exports to zero. It can be seen that for most producer countries, the effects of a ban of its exports on the population affected $\mathrm{GPA}_{0.5}$ have decreased from 2009 to the situation of 2013 (notably for Argentina, Germany or Ukraine). However, other countries have become more influential in this sense, especially in the case of the USA, which is not only the country affecting a greater number of the population, but also this effect has increased over the years.

We also carried out a Fractional regression analysis (Papke and Wooldridge, 1996) to examine the effects of population, network topology (as given by different CNA measures) and world region (North America versus S. America, Europe, Africa and Oceania) on the internal demand covered index (2) averaged for all possible scenarios considered. Different fractional model specifications for the conditional expectation are estimated using a quasi-maximum likelihood estimator (Ramalho et al., 2010). All the variables, except PageRankimporter and nominal dichotomous variables, were converted into their natural logarithm.

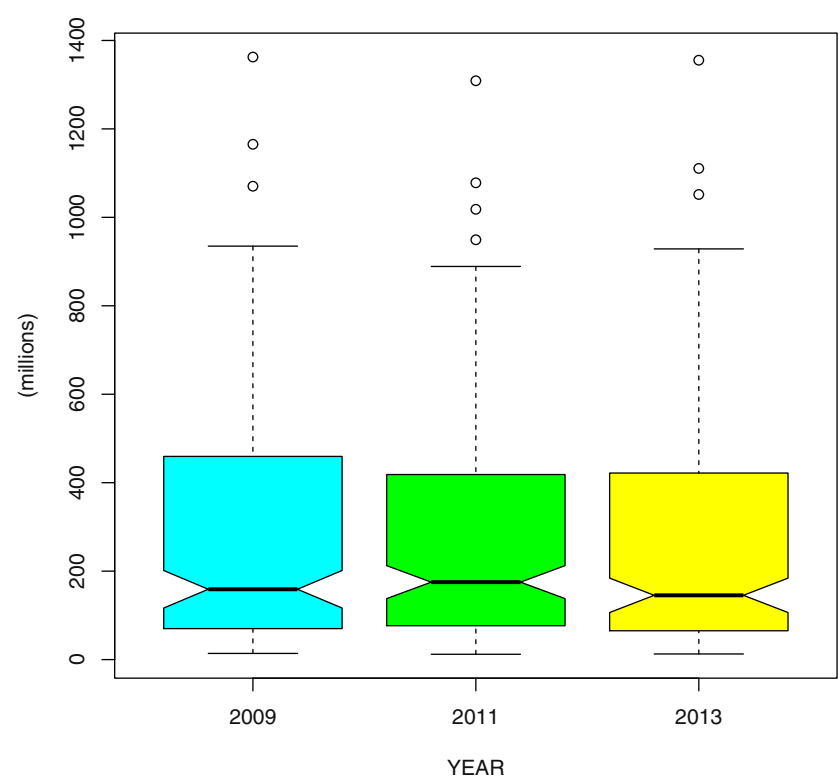

Fig. 3 Boxplot of population affected by production drops of $50 \%$ in one (or two) major producers 


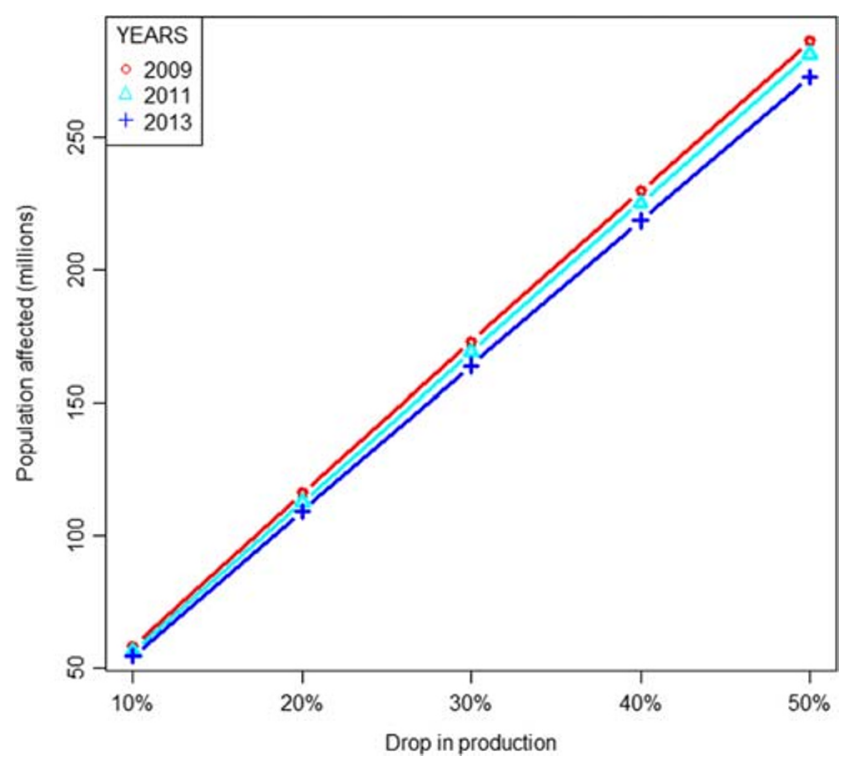

Fig. 4 Evolution of the population affected by different intensity levels of production crisis

Estimated results are shown in Table 6. It can be noticed that all estimates reveal the same conclusions in terms of their sign, however, with respect to significance, all the specifications are coincident, except for Complementary Log-Log (hereafter CLog-Log) that identifies one more explanatory variable, namely the logarithm of the total degree (denoted LDegree).

The results of the fractional regression do not confirm that highly populated countries have a positive capacity to handle the type of shock we are considering. However, with negative significant coefficients we find regressors such as the instrength of the countries. This shows how the dependency on the import of wheat can have a negative effect on the ability of countries to guarantee the appropriate supply of this cereal to fulfil the internal demand when some shocks are expected.
Another variable with a negative coefficient is the total degree of the node, which is the sum of its in- and out-degree. It seems that, in the short-term, a shock originating somewhere in the network, is likely to affect countries having many trading partners.

Regarding the regions, according to these regression results, countries in Europe, Asia and South America are in a better position to attend their internal demand under a shock event. In this regard, note that many large wheat producers are located in Europe and Asia. The P-test (Davidson and MacKinnon, 1981) was calculated to discriminate between alternative non-linear fractional model specifications. The Ptest results indicate that the Clog-Log model specification is more suitable. This may be due to the fact that Clog-Log describes an asymmetric pattern approach, where the conditional mean of the internal demand covered index increases slowly at small increments of cumulative distribution function (Cdf) and sharply when Cdf is close to unity.

\subsection{Global shock assessment}

Once the immediate effects on the wheat trade network of local shocks on the main producer countries have been analysed, it may be of interest to assess the effects provoked by a global supply shock in which all major producers limited their exports. Such global crises (e.g. due to a climateaffecting volcano eruption, a world war, a pandemic), although unlikely, has attracted the attention of some analysts in the field of food security. As an example, Jägermeyr et al. (2020) studied the effect on the world wheat production in a nuclear war between India and Pakistan. Such conflict would generate climate perturbations that would provoke a fall in wheat production worldwide of up to $11 \%$ over 5 years. This would affect cereal availability even for major producers. For instance, by year 4 Poland would lose a $33 \%$ of its current
Fig. 5 Difference (2013-2009) between the percentages of internal demand covered after $50 \%$ drops in production vs. GDP per capita

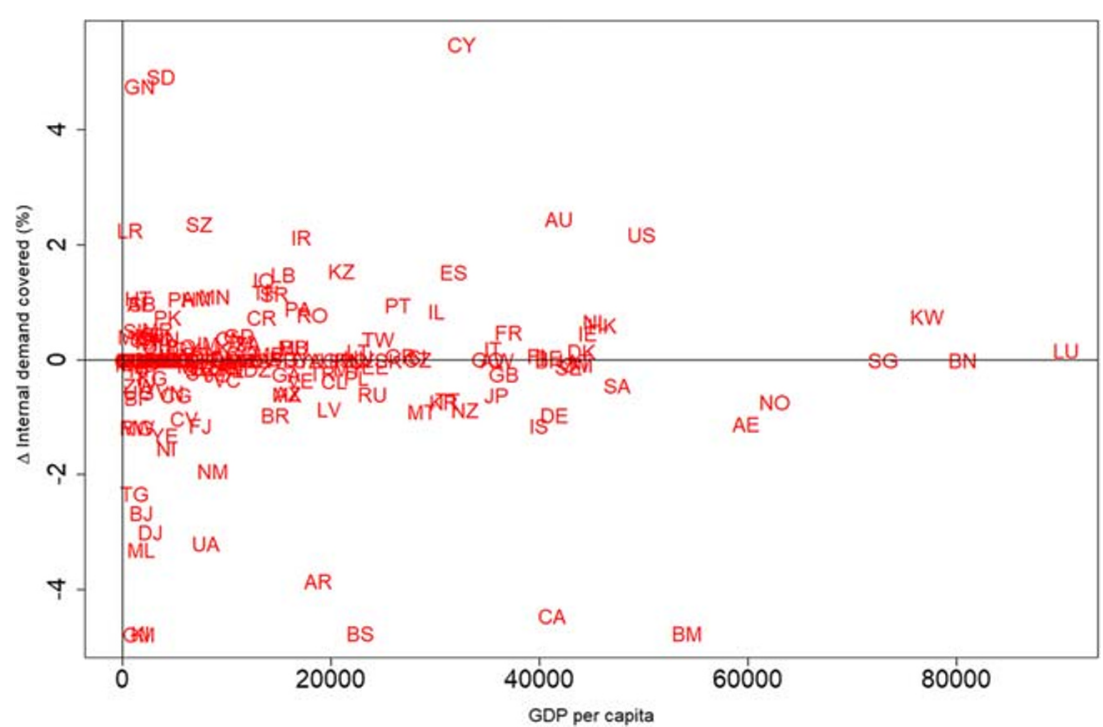



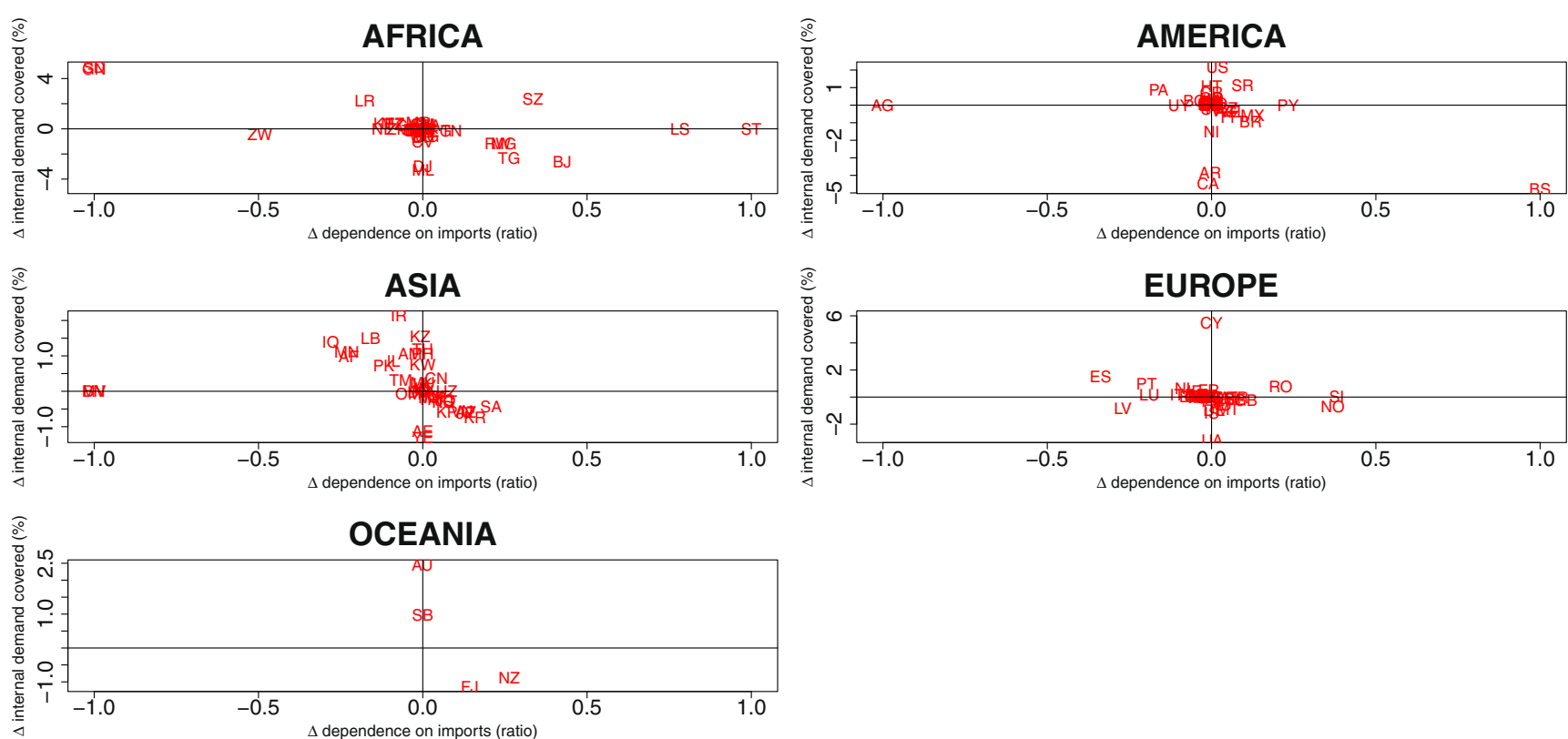

Fig. 6 Difference (2013-2009) between the percentages of internal demand covered after 50\% drops in production vs. difference in imports dependence ratios (2013-2009)

stock, with more severe restrictions in countries relying on imports (up to a $90 \%$ reduction in some African countries).

We can simulate this type of global shock using the current wheat trade network, assuming reductions of $10 \%, 20 \%$ and $30 \%$ in the production and export of all major producers (20 countries). The results show that under the current trade network, such restrictions would affect 574 million people in the less severe scenario, with only $30 \%$ of the 204 countries considered able to absorb the disturbances. Figure 8 shows the summary of the demand per country covered in each scenario, considering the current trade network.

Fig. 7 Evolution of the population affected by an export ban in one of the 20 largest wheat producers
It may be interesting at this point to comment on the current COVID-19 pandemic, to ascertain what would happen if, having already played havoc with the global economy, it was to lead also to a global supply shock in the wheat market. We first observe that given the uncertainty that this unexpected event produces, governments may be tempted to act as common households do, i.e., hoarding food as a strategic resource (Sulser and Dunston, 2020). This response would be aimed at trying to stabilise domestic prices as a result of the transient distribution problems provoked by the exceptional restrictions of movement imposed in many countries. Note, however, that

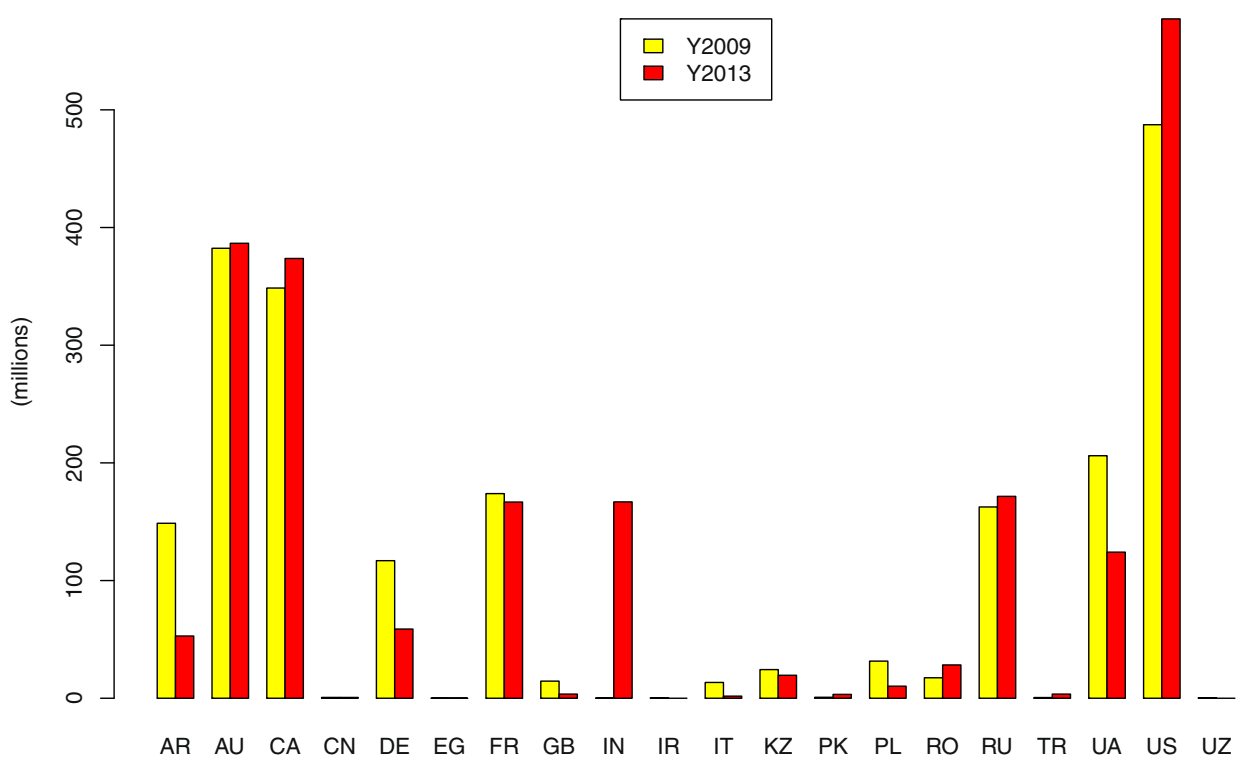


Table 6 Estimation results for the fractional regression models

\begin{tabular}{|c|c|c|c|c|}
\hline & Logit & Probit & $\log -\log$ & CLog-Log \\
\hline LPopulation & $\begin{array}{l}0.112 \\
(0.107)\end{array}$ & $\begin{array}{l}0.041 \\
(0.041)\end{array}$ & $\begin{array}{l}0.111 \\
(0.106)\end{array}$ & $\begin{array}{l}0.023 \\
(0.024)\end{array}$ \\
\hline LDegree & $\begin{array}{l}-0.148 \\
(0.096)\end{array}$ & $\begin{array}{l}-0.061 \\
(0.037)\end{array}$ & $\begin{array}{l}-0.146 \\
(0.095)\end{array}$ & $\begin{array}{l}-0.038^{*} \\
(0.023)\end{array}$ \\
\hline LInStrength & $\begin{array}{l}-0.213 * * * \\
(0.062)\end{array}$ & $\begin{array}{l}-0.082 * * * \\
(0.023)\end{array}$ & $\begin{array}{l}-0.211 \text { *** } \\
(0.062)\end{array}$ & $\begin{array}{l}-0.049 * * * \\
(0.012)\end{array}$ \\
\hline PageRank- importer & $\begin{array}{l}-0.002 \\
(0.016)\end{array}$ & $\begin{array}{l}-0.001 \\
(0.006)\end{array}$ & $\begin{array}{l}-0.002 \\
(0.016)\end{array}$ & $\begin{array}{l}-0.001 \\
(0.004)\end{array}$ \\
\hline SAmerica & $\begin{array}{l}0.351 \\
(0.220)\end{array}$ & $\begin{array}{l}0.145^{*} \\
(0.087)\end{array}$ & $\begin{array}{l}0.346 \\
(0.218)\end{array}$ & $\begin{array}{l}0.091 * \\
(0.053)\end{array}$ \\
\hline Europe & $\begin{array}{l}0.892 * * * \\
(0.294)\end{array}$ & $\begin{array}{l}0.364 * * * \\
(0.113)\end{array}$ & $\begin{array}{l}0.881 * * * \\
(0.292)\end{array}$ & $\begin{array}{l}0.226 * * * \\
(0.067)\end{array}$ \\
\hline Africa & $\begin{array}{l}0.278 \\
(0.263)\end{array}$ & $\begin{array}{l}0.115 \\
(0.105)\end{array}$ & $\begin{array}{l}0.275 \\
(0.261)\end{array}$ & $\begin{array}{l}0.073 \\
(0.064)\end{array}$ \\
\hline Asia & $\begin{array}{l}0.584 * * * \\
(0.162)\end{array}$ & $\begin{array}{l}0.242 * * * \\
(0.065)\end{array}$ & $\begin{array}{l}0.577 * * * \\
(0.160)\end{array}$ & $\begin{array}{l}0.152 * * * \\
(0.039)\end{array}$ \\
\hline Oceania & $\begin{array}{l}0.271 \\
(0.364)\end{array}$ & $\begin{array}{l}0.087 \\
(0.142)\end{array}$ & $\begin{array}{l}0.272 \\
(0.360)\end{array}$ & $\begin{array}{l}0.043 \\
(0.085)\end{array}$ \\
\hline Constant & $\begin{array}{l}5.029 * * * \\
(0.946)\end{array}$ & $\begin{array}{l}2.537 * * * \\
(0.365)\end{array}$ & $\begin{array}{l}5.024 * * * \\
(0.939)\end{array}$ & $\begin{array}{l}1.671 * * * \\
(0.216)\end{array}$ \\
\hline Pseudo $\mathrm{R}^{2}$ & 0.131 & 0.132 & 0.131 & 0.133 \\
\hline P-test $\mathrm{H}_{1}$ : Logit & - & $3.211^{*}$ & $4.323 * *$ & 2.441 \\
\hline P-test $\mathrm{H}_{1}$ : Probit & $5.588 * *$ & - & $5.695 * *$ & 2.215 \\
\hline P-test H1: Loglog & $4.142 * *$ & $3.150 *$ & - & 2.395 \\
\hline P-test H1: Cloglog & $6.719 * * *$ & $5.125 * *$ & $6.480 * * *$ & - \\
\hline
\end{tabular}

Notes: Dependent variable is the average of the internal demand covered $\mathrm{I}_{\mathrm{c}, \alpha}$ for all possible scenarios. Values in parenthesis are robust standard errors. *, ** and *** indicate statistically significant coefficient at $10 \%$, $5 \%$ and $1 \%$, respectively

such price increases do not need to happen. For example, in China the impact of COVID-19 on rice and wheat flour prices was insignificant (Yu et al., 2020). Major producers such as Russia, Ukraine, Kazakhstan, Kyrgyzstan and Romania imposed export limits (in the latter case just for one week after the intervention of the EU). Other countries, however, did not follow this path and during the initial months of the pandemic increased their exports figures (as was the case of France).

As pointed out by Torero Cullen (2020), trade restrictions generate scarcity and therefore panic, harming consumers as well as producers. Demand shocks occur at the same time as supply shocks. It is important that in these cases the supply chains do not break down, especially for staple commodities (such as wheat). Fortunately, wheat production is capital-intensive, unlike high-value commodities (such as fruits and vegetables), which are labour-intensive produces. Therefore, labour shortages due to COVID-19 restrictions on the movement of workers are not affecting cereal production, and only limited distribution problems could be expected.

In addition, the current global stocks of wheat are better than they were in the previous 2008 crisis and the 2020 wheat crop prospects are good, which does not make any drastic measures necessary. Nevertheless, using the partial-equilibrium International Model for Policy Analysis of Agricultural Commodities and Trade (IMPACT) model, developed by the International Food Policy Research Institute (IFPRI), Sulser and Dunston (2020) have estimated the effects of wheat trade restrictions in five ex-USSR countries. They expect a global $4 \%$ price increase and an increase of around 6 million people suffering chronic hunger (rising to 18 million if trade restrictions on rice are also implemented in South-East Asia and India). The paradox is that this could happen even when no scarcity is expected. Other studies have made an estimation of 130 million people who would face acute hunger due to border thickening, logistics shutdown, donor countries' recessions reducing food aid to poor countries, higher operation costs and collapse of household economies (Cardwell and Ghazalian, 2020).

\section{Discussion}

Wheat is one of the most important crops when discussing human food. For millions of people around the globe it is the basic source in their intake of calories and, for this reason, it is a major issue for most countries to guarantee the required amount of this cereal will reach their internal markets. However, most countries are not able to produce sufficient to fulfil their own demand, and therefore they have to rely on international trade to satisfy their needs, complementing their production and strategic stocks. This makes the world trade of wheat a very complex network, capturing the flow of cereal among all the agents involved.

As a first step, a complex network analysis of the network, using data from years 2009-2013, has been carried out. It has been found that the WTN shows a high degree of reciprocity and clustering; the degree and strength distributions follow a Power law distribution, and there are a small number of recurrent motifs in the network, in particular transitive ones. It has also been found that the WTN shows regional heterophily/ disassortativity, i.e. a tendency of countries to trade with other countries in the same region.

Regarding the analysis of the evolution of countries' vulnerability when a major production crisis occurs in any of the largest producers, crises of varying intensities have been simulated considering more than 200 combinations of major producers experiencing production shocks. The number of people initially affected by those local crises (i.e., before further actions are taken by the corresponding governments to counter their effects) was considered as the dependent variable. Our results show that in general, the most recent trading network (2013) shows a reduction in the number people affected when this type of production shortage occurs. In fact, according to Fig. 4 , in the case of the smaller crisis considered $(\alpha=10 \%)$ there is a reduction of $6.3 \%$ in the number of affected people 
Fig. 8 Internal demand covered by current wheat trade network under a global shock of different intensities

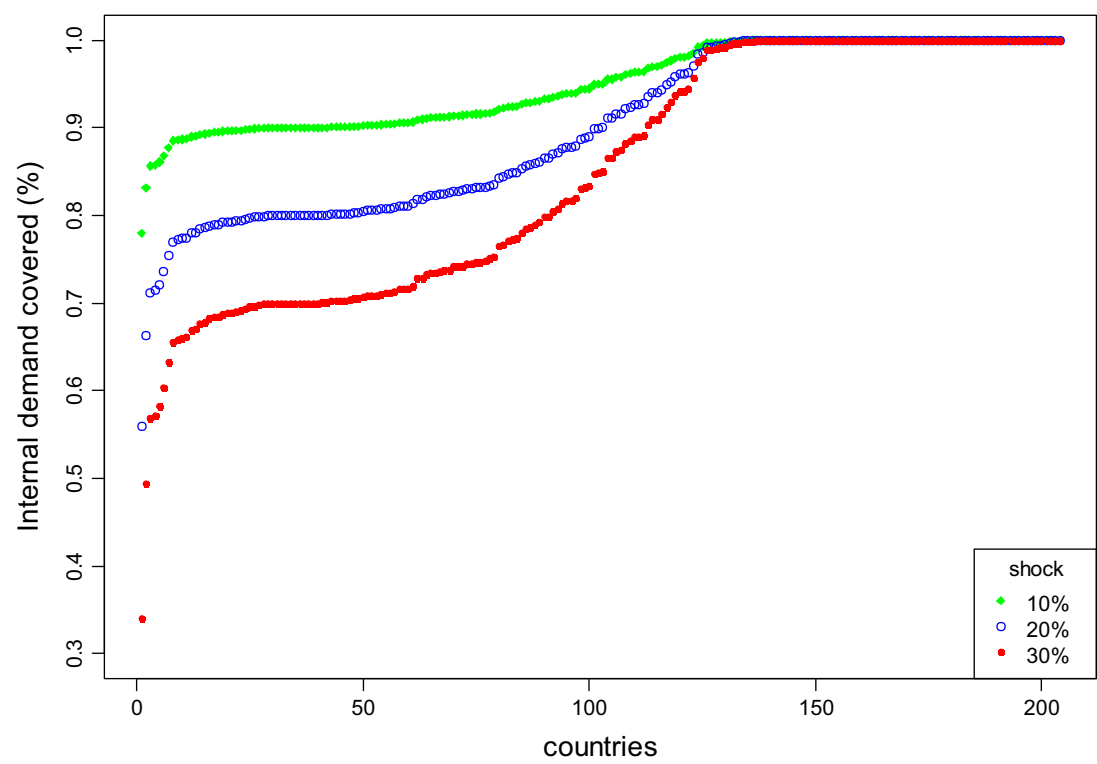

between the first and the last year of the 5-year period, while in the case of the $50 \%$ production drop, the reduction in the people affected in 2013 is $4.7 \%$ when compared with 2009 .

We have observed a relevant factor affecting the change in the vulnerability over the years. As shown in Fig. 5, for countries with higher per capita GDP the situation has not changed substantially in the period, while for those with lower per capita GDP there is a greater variability, with countries improving up to 4 points (such as Guinea or Sudan), while others are worsening by around 4 points (Gambia, Kiribati, Bahamas, and surprisingly, Canada). Obviously, countries relying on imports are far more vulnerable to events occurring in the supply regions.

Therefore, in general, although some countries clearly have not improved their vulnerability, the WTN as a whole has become more resilient in recent years, making fewer people vulnerable to those critical events. This is in the line with the "robust-yet-fragile" network paradigm as defined by Puma et al. (2015).

A fractional regression has been carried out and the results show that countries less dependent on imports can in general more capably attend to their internal demand when a shock occurs somewhere. Also, in terms of geography, from the point of view of their immediate ability to respond to these types of events, countries in Asia and Europe are in general better positioned.

In the case of a major disruption of global wheat trade, estimating the effects on wheat stocks and internal demand is a complex task, given the unpredictable political responses of national governments, compounded by the inherent uncertainty of the situation. Depending on the decisions taken, some importing countries could result in serious cereal shortage affecting millions of people. Note that, imposing any trade restrictions can have a cascading effect that in the end harms the market and consequently both consumers and producers, although more the former than the latter, and more the poorer than the wealthy. That is the curse of vulnerability.

With regard to the current COVID-19 pandemic, it has disrupted global supply chains in many sectors, including Agri-food sector. There is a consensus, however, that in the short-term its impact on wheat trade might not be big for several reasons. Thus, it is a capital-intensive crop, requiring relatively little labour input. The likelihood of logistics and transport disruptions are also low. Stock reserves are strong and production levels this year are expected to be high. There is the danger, however, that for political reasons, governments may respond to the uncertainty of the overall situation by limiting or banning wheat exports as well as by building up precautionary reserves as a protection against the effects of a protracted global health crisis. Such measures would affect global trade flows and would hurt all parts involved being counterproductive.

The main lesson for the market agents is that trade creates interdependencies, and consequently, while it can provide assistance in the case of local shocks originating on your own turf, it exposes countries to shocks and disruptions originating elsewhere and propagated through the trade links. Another significant lesson is that although costly, the role of reserves as buffers that can dampen the effects of supply shocks is important. Without such buffers, it is almost inevitable that just by the pure action of demand and supply forces, some countries (particularly, poorer countries) can be negatively affected by supply shocks in any major producer country. In the end, the overall effects of most supply shocks can be mitigated as the global through trade does not prevent the weakest nodes of the system from being severely hit.

It cannot be said that these results are unexpected but it is important nevertheless to be able to show and quantify them. Moreover, the analysis carried out also suggested preventive policy measures. Thus, one way to remedy the unequal 
distribution of the shortages induced by supply shocks would be by establishing common transnational reserves (at the regional level for example) that can be built up in boom years, thus helping stabilise the market in both directions.

As a caveat, it must be noted that how each country reacts at any particular time to supply shocks depends on many factors and political decisions; for this reason, these metrics at country level are just an approximation to this complex problem, which can provide some trends in the global evolution of the system resilience for its better understanding.

As limitations of this study, apart from the limited time span of the available data, it can be mentioned that the analysis carried out is based exclusively on physical flows and mass conservation equations. It does not take into account average commodity prices, neither the per capita GDP, nor the income elasticity of demand of the countries. Including such economic information that may enrich the analysis but would require other tools (e.g. regression analysis). Also, the study assumes the current decentralised working of the system and therefore does not explore certain global coordination possibilities that, for example on the occasion of the COVID-19 pandemic, might be put into place, for example, a Global Distributed Reserve Fund. The idea is that an interconnected and integrated system like WTN with decentralised functioning requires some stabilisation mechanism to mitigate and absorb both demand and supply shocks. We believe that this is an interesting topic for further research.

Supplementary Information The online version contains supplementary material available at https://doi.org/10.1007/s12571-020-01117-9.

Acknowledgements This research was carried out with the financial support of the Spanish Ministry of Economy, Industry and Competitiveness, and the European Regional Development Fund (ERDF), grant DPI201785343-P.

\section{References}

Borgatti, S. P., Everett, M. G., \& Freeman, L. C. (2002). Ucinet for windows: Software for social network analysis. Harvard: Analytic Technologies.

Brin, S., \& Page, L. (1998). The anatomy of a large-scale Hypertextual web search engine. Computer Networks and ISDN Systems, 30, 107-117.

Burkholz, R., \& Schweitzer, F. (2019). International crop trade networks: The impact of shocks and cascades. Environmental Research Letters, 14, 114013.

Cardwell, R., \& Ghazalian, P. L. (2020). COVID-19 and international food assistance: Policy proposals to keep food flowing. World Development, 135, 105059.

Clauset, A., Shalizi, C. R., \& Newman, M. E. J. (2009). Power-law distributions in empirical data. SIAM Review, 51(4), 661-703.

Costa, L. D. F., Rodrigues, F. A., Travieso, G., \& Villas Boas, P. R. (2007). Characterization of complex networks: A survey of measurements. Advances in Physics, 56, 167-242.
d'Amour, C. B., Wenz, L., Kalkuhl, M., Steckel, J. C., \& Creutzig, F. (2016). Teleconnected food supply shocks. Environmental Research Letters, 11, 035007.

Davidson, R., \& MacKinnon, J. (1981). Several tests for model specification in the presence of alternative hypotheses. Econometrica, 49, 781-793.

D’Odorico, P., Carr, J., Laio, F., Ridolfi, L., \& Vandoni, S. (2014). Feeding humanity through global food trade. Earth's Future, 2, 458-469.

Dong, C., Yin, Q., Lane, K. J., Yan, Z., Shi, T., Liu, Y., \& Bell, M. L. (2018). Competition and transmission evolution of global food trade: A case study of wheat. Physica A, 509, 998-1008.

Dupas, M.-C., Halloy, J., \& Chatzimpiros, P. (2019). Time dynamics and invariant subnetwork structures in the world cereals trade network. PLoS One, 14(5), e0216318.

Ercsey-Ravasz, M., Toroczkai, Z., Lakner, Z., \& Baranyi, J. (2012). Complexity of the international agro-food trade network and its impact on food safety. PLoS One, 7(5), e37810.

Fair, K. R., Bauch, C. T., \& Anand, M. (2017). Dynamics of the global wheat trade network and resilience to shocks. Scientific Reports, 7, 7177.

FAO (2018). FAOSTAT. Online statistical database: Production (available at http://faostat3.fao.org/download/Q/QC/E).

Fortunato, S. (2010). Community detection in graphs. Physics Reports, 486, 75-174.

Fraser, E. D. G., Simelton, E., Termansen, M., Gosling, S. N., \& South, A. (2013). "Vulnerability hotspots": Integrating socio-economic and hydrological models to identify where cereal production may decline in the future due to climate change induced drought. Agricultural and Forest Meteorology, 170, 195-205.

Gephart, J. A., Rovenskaya, E., Dieckmann, U., Pace, M. L., \& Brännström, A. (2016). Vulnerability to shocks in the global seafood trade network. Environmental Research Letters, 11, 035008.

Jägermeyr, J., Robock, A., Elliott, J., Müller, C., Xia, L., Khabarov, N., Folberth, C., Schmid, E., Liu, W., Zabel, F., Rabin, S. S., Puma, M. J., Heslin, A., Franke, J., Foster, I., Asseng, S., Bardeen, C. G., Toon, O. B., \& Rosenzweig, C. (2020). A regional nuclear conflict would compromise global food security. Proceedings of the National Academy of Sciences, 117(13), 7071-7081.

Jones, A. W., \& Phillips, A. (2016). Historic food production shocks: Quantifying the extremes. Sustainability, 8, 427.

Kummu, M., Kinnunen, P., Lehikoinen, E., Porkka, M., Queiroz, C., Röös, E., Troell, M., \& Weil, C. (2020). Interplay of trade and food system resilience: Gains on supply diversity over time at the cost of trade independency. Global Food Security, 24, 100360.

Larochez-Dupraz, C., \& Huchet-Bourdon, M. (2016). Agricultural support and vulnerability of food security to trade in developing countries. Food Security, 8, 1191-1206.

Marchand, P., Carr, J. A., Dell'Angelo, J., Fader, M., Gephart, J. A., Kummu, M., Magliocca, N. R., Porkka, M., Puma, M. J., Ratajczak, Z., Rulli, M. C., Seekell, D. A., Suweis, S., Tavoni, A., \& D’Odorico, P. (2016). Reserves and trade jointly determine exposure to food supply shocks. Environmental Research Letters, 11, 095009.

Milo, R., Shen-Orr, S., Itzkovitz, S., Kashtan, N., Chklovskii, D., \& Alon, U. (2002). Network motifs: Simple building blocks of complex networks. Science, 298, 824-827.

Newman, M. E. J. (2003). The structure and function of complex networks. SIAM Review, 45, 167-256.

Newman, M. E. J. (2004). Detecting community structure in networks. European Physical Journal B, 38, 321-330.

Newman, M. E. J. (2006). Finding community structure using the eigenvectors of matrices. Physical Review E, 74, 036104.

Papke, L. E., \& Wooldridge, J. M. (1996). Econometric methods for fractional response variables with an application to $401(\mathrm{k})$ plan participation rates. Journal of Applied Econometrics, 11(6), 619-632. 
Puma, M. J., Bose, S., Chon, S. Y., \& Cook, B. I. (2015). Assessing the evolving fragility of the global food system. Environmental Research Letters, 10, 024007.

Ramalho, E. A., Ramalho, J. J. S., \& Henriques, P. D. (2010). Fractional regression models for second stage DEA efficiency analyses. Journal of Productivity Analysis, 34, 239-255.

Sartori, M., \& Schiavo, S. (2015). Connected we stand: A network perspective on trade and global food security. Food Policy, 57, 114-127.

Selim, K. S., \& Abdalbaki, S. M. (2019). On the relationship between virtual water network and crops intra-trade among Nile basin countries. Water Policy, 21, 481-495.

Sulser, T., Dunston, S (2020). COVID-19-related trade restrictions on rice and wheat could drive up prices and increase hunger. IFPRI blog. Available: https://www.ifpri.org/blog/covid-19-related-traderestrictions-rice-and-wheat-could-drive-prices-and-increase-hunger

Tamea, S., Laio, F., \& Ridolfi, L. (2016). Global effects of local foodproduction crises: A virtual water perspective. Scientific Reports, 6 , 18803

Torero Cullen, M. (2020). COVID-19 and the risk to food supply chains: How to respond? FAO. Available at: http://www.fao.org/3/ ca8388en/CA8388EN.pdf\#page $=1 \&$ zoom $=160,232,842$

Torreggiani, S., Mangioni, G., Puma, M. J., \& Fagiolo, G. (2018). Identifying the community structure of the food-trade international multi-network. Environmental Research Letters, 13, 054026.

Vora, N., Fath, B. D., \& Khanna, V. A. (2019). Systems approach to assess trade dependencies in U.S. food-energy-water Nexus. Environmental Science Technology, 53(18), 10941-10950.

Wang, C. (2010). A Social Network Analysis of International Wheat Trade, proceedings of the $3 \mathrm{rd}$ international conference on information management, innovation management and industrial engineering, 26-28 November 2010. China: Kunming.

Wasserman, S., \& Faust, K. (1994). Social network analysis: Methods and applications. Cambridge, UK: Cambridge University Press.

Yu, X., Liu, C., Wang, H., \& Feil, J. H. (2020). The impact of COVID-19 on food prices in China: Evidence of four major food products from Beijing, Shandong and Hubei provinces. China Agricultural Economic Review, 12(3), 445-458.

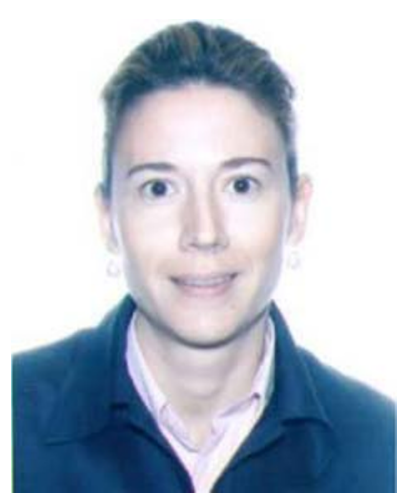

Ester Gutiérrez-Moya is a Professor of Quantitative Methods in Management in the Department of Industrial Management at the University of Seville. She holds a Ph.D from the University of Seville and a Master Science in Statistics, University of Seville, Spain. She has been a visiting professor at the Universities of California and at the Politecnico di Milano. She has published papers in scientific journals such as Journal of Cleaner Production, European Journal of Forest Research, Computers and Operations Research, etc.

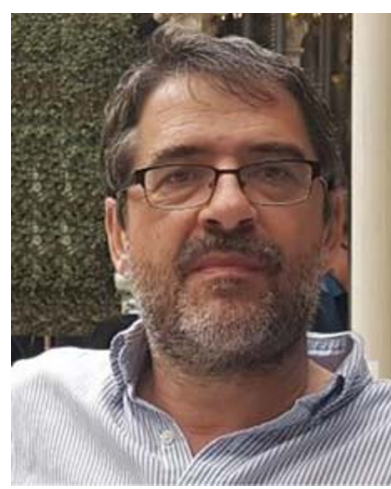

Belarmino Adenso-Díaz is a Professor of Operations Management at the Industrial Engineering School of the University of Oviedo in Spain. He has been a visiting professor at the Universities of Colorado and Michigan. He has authored four books, and published articles in scientific journals such as the Agricultural Systems, Operations Research, Journal of Operations Management, Production and Operations Management, European Journal of Operational Research, International Journal of Production Research, Omega, etc. He is associate editor of the Journal of Heuristics and Omega

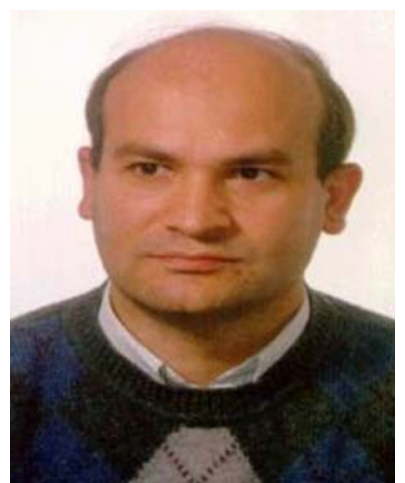

Sebastián Lozano is a Professor of Quantitative Methods in Management in the Department of Industrial Management at the University of Seville. He holds a $\mathrm{Ph} . \mathrm{D}$ from the University of Seville and a Master of Engineering in Industrial Management from the Katholieke Universiteit Leuven. His current research interests are in complex networks analysis, logistics and efficiency. 